\title{
Insulin Therapy for Hyperglycemia Management in Critically Ill Patients
}

\author{
Darla Eastman*, Jared Butler, Shannon Dicken, Michelle Bottenberg \\ College of Pharmacy and Health Sciences, Drake University, Des Moines, USA \\ Email: *darla.eastman@drake.edu, jared.butler@drake.edu, shannon.dicken@drake.edu, michelle.bottenberg@drake.edu
}

How to cite this paper: Eastman, D., Butler, J., Dicken, S. and Bottenberg, M. (2021) Insulin Therapy for Hyperglycemia Management in Critically Ill Patients. Journal of Diabetes Mellitus, 11, 317-327. https://doi.org/10.4236/jdm.2021.115025

Received: September 22, 2021

Accepted: November 15, 2021

Published: November 18, 2021

Copyright $\odot 2021$ by author(s) and Scientific Research Publishing Inc. This work is licensed under the Creative Commons Attribution International License (CC BY 4.0).

http://creativecommons.org/licenses/by/4.0/

(c) (i) Open Access

\begin{abstract}
Hyperglycemia is associated with increased morbidity and mortality in critically ill patients and requires treatment; however, hypoglycemia is also detrimental to patients and must be avoided. Maintaining blood glucose between $140-180 \mathrm{mg} / \mathrm{dL}$ for critically ill patients improves outcomes. Very frequent glucose monitoring and adjustment of intravenous insulin infusion remains the standard of care to reach blood glucose goals but is also labor intensive. Emerging technology for continuous glucose monitoring that may include notifications or automated communication with an insulin delivery system may improve the maintenance of blood glucose in range and avoid hypoglycemia and hyperglycemia.
\end{abstract}

\section{Keywords}

Insulin, Critical Care, Critically Ill, Hyperglycemia, Continuous Glucose Monitoring

\section{Introduction}

Hyperglycemia is a common condition among critically ill patients. Persistent hyperglycemia, defined by steady periods of blood glucose levels above $180 \mathrm{mg} / \mathrm{dL}$, is the recommended point at which insulin therapy should be started in hospitalized patients [1] [2] [3]. Clinicians in critical care settings are often challenged by the onset and treatment of hyperglycemia due to its association with increased risk of adverse patient outcomes, such as lengthened recovery periods, impaired wound healing, and immunosuppression [4]. Stress hyperglycemia, often onset due to acute physical trauma, is also related to other complications. Patients who present with acute hyperglycemia after an ischemic stroke are at an increased risk for congestive heart failure [5]. Hyperglycemia in patients recovering from a cerebral aneurysm is associated with poorer cognitive recovery 
and decreased neurological function compared to normoglycemic patients [6]. Additionally, hyperglycemia increases the risk for patients to exhibit clinical manifestations of critical illness polyneuropathy, such as prolonged stays in intensive care and lengthened use of mechanical ventilation [7]. Furthermore, hyperglycemia is correlated to increased in-patient mortality [8] [9]. In patients who have experienced myocardial infarction, hyperglycemia is associated with increased troponin I levels and increased tissue damage, leading to a higher risk of mortality [10]. Presentation of acute hyperglycemia after ischemic or hemorrhagic strokes is also shown to increase mortality [11]. Recently, hyperglycemia has been found to increase the risk of mortality and the likelihood of requiring mechanical ventilation in critically ill patients infected with COVID-19 [12].

Several studies have shown that hyperglycemia increases the prevalence of adverse effects in patients with and without previously diagnosed diabetes; however, acute hyperglycemia has been observed to have a greater risk of mortality in patients without any history of chronic hyperglycemia than those with an existing diabetes diagnosis [7] [10] [11]. Without considering any previous diagnoses of hyperglycemia, acute physical stress increases the release of cortisol and counter-regulatory hormones, which work to increase gluconeogenesis and insulin resistance, respectively [13]. On top of physiological stressors, exogenous promoters of hyperglycemia may include catecholamine or corticosteroid use, parenteral nutrition, intravenous medication in dextrose solution, or infusion of blood products preserved with glucose [4].

Following the publication of the NICE-SUGAR study in 2009, the American Association of Clinical Endocrinologists and the American Diabetes Association (ADA) issued joint guidelines with adjusted blood glucose target goals for treating hyperglycemia in hospitalized patients [6]. The recommendation continues to be to begin insulin therapy when blood glucose levels exceed $180 \mathrm{mg} / \mathrm{dL}$ and to maintain levels between $140-180 \mathrm{mg} / \mathrm{dL}$ [14] [15]. Comparatively, the Society of Critical Care Medicine maintains slightly more strict guidelines, recommending initiation of insulin therapy when blood glucose levels exceed 150 $\mathrm{mg} / \mathrm{dL}$ and to maintain levels below that threshold value [16]. While the majority of critical care clinicians will adhere to the less stringent glucose targets, certain patients may be treated to maintain blood glucose levels between 110 - 140 $\mathrm{mg} / \mathrm{dL}$ if there is minimal risk of hypoglycemia [15]. Treating hyperglycemia with insulin therapy and the importance of glycemic maintenance in critically ill patients are universally accepted.

Several studies have concluded that basal-bolus insulin is the safest way to maintain glycemic control in the acute care setting while minimizing the risk of hypoglycemia [17] [18] [19]. However, use of a continuous intravenous insulin infusion is the recommended course of action when treating hyperglycemia for meeting adjusted glycemic targets in critically ill patients [3] [20] [21]. Furthermore, critically ill patients are at high risk for fluctuating blood glucose levels, 
and short-acting insulin has a faster onset and a much shorter half-life to limit rebound hypoglycemia and carryover hyperglycemia once the insulin infusion is stopped [20]. In critically ill patients, blood glucose levels should be checked at least every two hours via arterial or venous blood sampling to prevent hypoglycemia [16].

This review will examine the current evidence supporting optimal glucose control in critically ill patients, as well as consider clinical applications for clinicians who practice in this setting.

\section{Literature Review}

\subsection{Blood Glucose Goals}

Hyperglycemia management has evolved significantly in the past twenty years. Throughout the early 2000s, the general consensus was that glucose control in the intensive care unit was best managed with a goal glucose range between 80 and $110 \mathrm{mg} / \mathrm{dL}$ to improve outcomes [22] [23] [24]. In 2009 and throughout the following months and years, new research was released, including a set of articles from the study group Normoglycemia in Intensive Care Evaluation-Survival Using Glucose Algorithm Regulation (NICE-SUGAR). From the NICE-SUGAR study, there have been three separate publications highlighted in Table 1.

In March 2009, original data from NICE-SUGAR was published [25]. The study's aim was to identify the optimal blood glucose target range for patients who were critically ill. This parallel-group, multi-national, randomized control trial was divided into intensive treatment control (between 81 and $108 \mathrm{mg} / \mathrm{dL}$ ) and conventional control (less than or equal to $180 \mathrm{mg} / \mathrm{dL}$ ), with the primary outcome of death from any cause at 90 days after randomization. Patients were well balanced based on SOFA and APACHE II scores, and intention to treat analysis was performed. Beyond the primary outcome, a safety outcome of severe hypoglycemia (a glucose level less than or equal to $40 \mathrm{mg} / \mathrm{dL}$ ) was also assessed. In contrast to previous landmark trials, NICE-SUGAR demonstrated an increased risk of death at ninety days in the intensive glucose control group, with a number needed to harm of 38 . In addition, there was a statistically significant increase in the frequency of severe hypoglycemia at $6.8 \%$ versus $0.5 \%$ in the intensive versus conventional glucose control, $(\mathrm{p}<0.001)$.

The subsequent sub-analysis from the NICE-SUGAR group was published in 2012 [27]. The study's aim was to determine if death could be attributed to hypoglycemia in the critically ill. The data were reviewed for occurrences of severe hypoglycemia (a glucose level less than or equal to $40 \mathrm{mg} / \mathrm{dL}$ ) and moderate hypoglycemia (a glucose level of $41-70 \mathrm{mg} / \mathrm{dL}$ ). In reviewing the results, patients who experienced severe or moderate hypoglycemia had more prolonged ICU and hospital stays than those without hypoglycemic events, although no difference was seen in mortality in each group based on hypoglycemia status. Within the study population, 3089 patients did not experience hypoglycemia, 2714 had moderate hypoglycemia, and 223 had severe hypoglycemia. There was a $23.5 \%$, 
Table 1. Literature review on blood glucose targets for critically ill patients.

\begin{tabular}{|c|c|c|c|c|c|}
\hline Trial & Study Design & Patients & Comparator Groups & Findings & Comments \\
\hline $\begin{array}{l}\text { NICE-SUGAR } \\
\text { study } \\
\text { investigators. } \\
{[25]}\end{array}$ & $\begin{array}{l}\text { Randomized } \\
\text { post-hoc analysis }\end{array}$ & $\begin{array}{l}\text { Critically-ill } \\
\text { patients in } \\
\text { intensive care } \\
\text { units }(\mathrm{N}=6026)\end{array}$ & $\begin{array}{l}\text { Intensive glucose } \\
\underline{\text { control: }} \\
\text { BG range } 81-108 \\
\mathrm{mg} / \mathrm{dL} \\
\text { Conventional glucose } \\
\underline{\text { control: }}\end{array}$ & $\begin{array}{l}\text { Mortality: } \\
\text { No difference between } \\
\text { groups } \\
\text { Morbidity: } \\
\text { Moderate/severe } \\
\text { hypoglycemia correlated }\end{array}$ & $\begin{array}{l}\text { Mortality increased in } \\
\text { moderate/severe } \\
\text { hypoglycemia, } \\
\text { regardless of treatment } \\
\text { group }\end{array}$ \\
\hline & & & Target $180 \mathrm{mg} / \mathrm{dL}$ or less & swith longer ICU stays & \\
\hline $\begin{array}{l}\text { Griesdale, } \\
\text { DEG; } \\
\text { et al. [26] }\end{array}$ & $\begin{array}{l}\text { Meta-analysis of } \\
26 \text { trials }\end{array}$ & $\begin{array}{l}\text { Critically-ill } \\
\text { patients in } \\
\text { intensive care } \\
\text { units }\end{array}$ & -- & $\begin{array}{l}\text { Intensive glucose control } \\
\text { had no effect on the overall } \\
\text { mortality rate }\end{array}$ & $\begin{array}{l}\text { Intensive insulin therapy } \\
\text { may be beneficial to } \\
\text { patients admitted to a } \\
\text { surgical ICU }\end{array}$ \\
\hline $\begin{array}{l}\text { NICE-SUGAR } \\
\text { study } \\
\text { investigators. } \\
{[27]}\end{array}$ & $\begin{array}{l}\text { Randomized } \\
\text { post-hoc analysis }\end{array}$ & $\begin{array}{l}\text { Critically-ill } \\
\text { patients in } \\
\text { intensive care } \\
\text { units }(\mathrm{N}=6026)\end{array}$ & $\begin{array}{l}\text { Moderate hypoglycemia: } \\
\text { BG range } 41-70 \mathrm{mg} / \mathrm{dL} \\
\text { Severe hypoglycemia: } \\
\text { BG range } \\
40 \mathrm{mg} / \mathrm{dL} \text { or less }\end{array}$ & $\begin{array}{l}\text { Length of Stay: } \\
\text { Increased for those } \\
\text { experiencing moderate or } \\
\text { severe hypoglycemia } \\
\text { Mortality: } \\
\text { No difference between } \\
\text { groups }\end{array}$ & $\begin{array}{l}\text { No causal relationship } \\
\text { could be established, but } \\
\text { an association was } \\
\text { found between } \\
\text { hypoglycemic events } \\
\text { and death. }\end{array}$ \\
\hline $\begin{array}{l}\text { NICE-SUGAR } \\
\text { study } \\
\text { investigators. } \\
{[28]}\end{array}$ & $\begin{array}{l}\text { International } \\
\text { randomized- } \\
\text { controlled } \\
\text { trial subgroup } \\
\text { follow-up } \\
\text { analysis }\end{array}$ & $\begin{array}{l}\text { Traumatic brain } \\
\text { injury }(\mathrm{TBI}) \\
\text { patients in } \\
\text { intensive care } \\
\text { units }(\mathrm{N}=391)\end{array}$ & $\begin{array}{l}\frac{\text { Intensive glucose }}{\text { control: }} \\
\text { BG range } 81-108 \\
\mathrm{mg} / \mathrm{dL} \\
\text { Conventional glucose } \\
\frac{\text { control: }}{\text { Target } 180 \mathrm{mg} / \mathrm{dL} \text { or less }}\end{array}$ & $\begin{array}{l}\text { Mortality: } \\
\text { No difference between } \\
\text { groups } \\
\text { Morbidity: } \\
\text { Glasgow outcomes score } \\
\text { sunchanged between groups }\end{array}$ & $\begin{array}{l}\text { Follow-up of TBI } \\
\text { patients who } \\
\text { participated in the } \\
\text { NICE-SUGAR study. }\end{array}$ \\
\hline $\begin{array}{l}\text { Krinsley, JS. } \\
\text { [29] }\end{array}$ & $\begin{array}{l}\text { Literature review } \\
\text { of observational } \\
\text { cohort studies }\end{array}$ & $\begin{array}{l}\text { Critically-ill } \\
\text { patients in } \\
\text { intensive care } \\
\text { units }\end{array}$ & -- & $\begin{array}{l}\text { Hypoglycemia, } \\
\text { hyperglycemia, and more } \\
\text { glucose variability are each } \\
\text { associated with increased } \\
\text { risk of death. } \\
\text { Time in range }>80 \% \text { for } \\
\text { nondiabetics is strongly and } \\
\text { independently associated } \\
\text { with survival. }\end{array}$ & $\begin{array}{l}\text { Limiting glucose } \\
\text { variability and } \\
\text { improving the time } \\
\text { within the goal range } \\
\text { may be the key target to } \\
\text { improving outcomes. }\end{array}$ \\
\hline $\begin{array}{l}\text { Perez, A; } \\
\text { et al. [18] }\end{array}$ & Meta-analysis & $\begin{array}{l}\text { Hospitalized } \\
\text { patients, both } \\
\text { critically and } \\
\text { non-critically ill }\end{array}$ & -- & $\begin{array}{l}\text { Extremes of blood glucose } \\
\text { led to poor outcomes. A } \\
\text { target glucose range of } \\
110-180 \mathrm{mg} / \mathrm{dL} \text { is most } \\
\text { appropriate for critically ill } \\
\text { and noncritically ill patients. }\end{array}$ & $\begin{array}{l}\text { Continuous intravenous } \\
\text { insulin infusion is } \\
\text { preferred for critically ill } \\
\text { patients and scheduled } \\
\text { basal-bolus-correction } \\
\text { insulin is preferred in } \\
\text { noncritically ill patients. }\end{array}$ \\
\hline
\end{tabular}

$28.5 \%$, and $35.4 \%$ death rate in each population. Although statistical significance was not reached, the hypoglycemia rate within each treatment group may be 
more clinically significant within the intensive treatment group $(74.2 \%$ moderate hypoglycemia and 6.9\% severe hypoglycemia) than the conventional group $(15.8 \%$ moderate and $0.5 \%$ severe hypoglycemia). The study authors noted that no causal relationship could be fully established, but an association appeared to be present based on the instance of hypoglycemia.

A further sub-group analysis was published in 2015 reviewing traumatic brain injury patients (TBI) [28]. A total of 391 TBI study patients were identified. This population split into $51.9 \%$ in the intensive control group and $48.1 \%$ in the conventional control group. This review did not demonstrate any differences in the outcome of death between either intervention group at 90 days or two years post-randomization. The only statistically significant difference was in the occurrence of severe hypoglycemia (4.9\% versus $0 \%, \mathrm{p}=0.003)$ and moderate hypoglycemia $(79.2 \%$ versus $9 \%, \mathrm{p}<0.0001)$ in the intensive and conventional control groups.

\subsection{Blood Glucose Monitoring}

Blood glucose monitoring is an essential component of hyperglycemia management. Hospitalized patients' glucose is commonly monitored using capillary blood from a fingerstick and a glucometer [15]. For patients who are critically ill and receiving insulin therapy via intravenous infusion, frequent monitoring every 30 minutes to two hours is standard.

While significant research has been conducted on determining the proper glucose target range, investigators are also focusing on how to achieve these desired glucose ranges. Continuous glucose monitoring systems (CGMs), which automatically provide glucose values every few minutes, may theoretically increase the effectiveness of glucose control, as well as minimize the risk of hypoglycemic events by detecting the rate of change and giving a timelier alert to make adjustments. In addition to potentially improving glycemic control, further benefits may include reducing the number of blood samples and blood loss, nursing workload, and costs. CGM sensors can be invasive (intravascular blood sampling or sensing devices that remove blood), minimally invasive (subcutaneous placement of a sensor), or noninvasive (transdermal), and since they measure different compartments, it can lead to differing values [30]. Although invasive CGMs are the only FDA approved option for ICU patients, several disadvantages exist that limit their use: they are invasive and thus associated with vascular complications such as thrombosis and catheter occlusion, they require a higher implementation resource and care burden, and finally they are only reserved for ICU settings and cannot be used when patient transfer to other levels of care [30]. As of this publication, subcutaneous CGMs have not been FDA-approved for use in hospitalized patients. However, it is postulated that since they allow for more frequent monitoring, they would consequently offer additional capability to identify glucose changes and to maintain glucose in range. A randomized controlled study of 144 patients evaluated whether CGMs in critically ill patients 
could improve glucose management compared with standard point-of-care (POC) glucose monitoring [31]. The CGMs were programmed to alarm if glucose was outside goal range and were utilized every fifteen minutes to two hours per protocol. Time in range was significantly improved with the use of CGMs, while mean glucose and proportion of hypoglycemic events were similar [31]. In a similar randomized controlled trial, CGMs were found to be as effective as POC glucose monitoring in maintaining blood glucose in range while reducing nursing workload and daily care costs [32]. More research is required before CGMs will be able to replace point of care blood glucose testing, but this technology is very promising.

\subsection{Insulin Therapy}

Insulin infusion therapy (IIT) has long been the standard treatment for critically ill patients with hyperglycemia [ADA 2021 Guidelines]. IIT must be managed through a protocol that accounts for current glucose levels as well as direction and magnitude of change in levels. IIT has a quick onset and is readily titrated, which makes it ideal for achieving glycemic targets in critically ill patients. However, IIT is labor-intensive for the care team, often requiring very frequent blood glucose monitoring, dedicated intravenous access, dose change calculations, and dosing double-checks. Paper-based or computerized protocols have been shown to achieve and maintain blood glucose targets and minimize hypoglycemia [33] [34]. However, a standardized protocol does not exist, and extensive variation exists among institutions.

The future may see technology continue to advance to where closed-loop systems may be utilized that continuously monitor glucose levels and automatically communicate with the insulin distribution system and adapt to changing insulin requirements. Preliminary studies have demonstrated the ability to achieve and maintain blood glucose goals safely [35]. Larger studies in critical care populations may be needed to assess the utility and economic feasibility of these technologies.

As patients stabilize in the critical care setting, transitioning from intravenous to subcutaneous insulin will need to occur to allow the patient to transfer out of the critical care setting. The Endocrine Society recommends starting subcutaneous insulin one to two hours before discontinuing the intravenous insulin and point of care monitoring for insulin adjustments after that [36]. Similarly, the ADA guidelines recommend development of an institution-specific transition protocol to calculate basal insulin doses based on the last six hours of a stable insulin infusion and to give basal insulin two hours before stopping the insulin infusion [15].

There have been a limited number of studies evaluating the transition from intravenous to subcutaneous insulin. Avanzini et al. evaluated a standardized protocol in patients after acute coronary syndrome. This study calculated total daily insulin needs based on the average insulin infusion rate from the preceding twelve hours, divided as $50 \%$ basal and $50 \%$ bolus insulin. The results demon- 
strated that $70.8 \%$ of patients were in the range of 80 to $160 \mathrm{mg} / \mathrm{dL}(80-200$ $\mathrm{mcg} / \mathrm{dL}$ post-prandial), and $26.8 \%$ of patients experienced hypoglycemia $(<70$ $\mathrm{mg} / \mathrm{dL}$ ) in the three days after changing to the basal-bolus regimen [37]. Another study in 2016 retrospectively looked at patients who converted from an insulin infusion to subcutaneous insulin. The groups in the study were based on the percent (less than $50 \%, 50 \%-59 \%, 60 \%-69 \%, 70 \%-79 \%$, and $80 \%$ or higher) of subcutaneous basal insulin given compared to a calculated 24-hour insulin need based upon the six hours before the transition. The results showed the 50\% $59 \%$ group had the highest occurrence of glucose levels between $70-150 \mathrm{mg} / \mathrm{dL}$, with $68 \%$ of the readings in this range. The $<50 \%$ group had the least effective achievement of $70-150 \mathrm{mg} / \mathrm{dL}$ with only $46 \%$ of the readings in that range. Hypoglycemia occurred in every group except the $50 \%-59 \%$ and $60 \%-69 \%$ groups. Although there are many confounders, the authors concluded that utilizing basal insulin at $50 \%-59 \%$ of the 24 -hour insulin need may be safe [38].

Based on the information available, utilization of stable, recent (six to twelve hours) insulin requirements to calculate a daily insulin need and initiating basal insulin two hours before stopping the insulin infusion appear to be best practices. It may be reasonable to consider using $50 \%$ of the 24 -hour insulin needed as basal insulin. Furthermore, clinicians must balance all the variables (nutrition, steroid use, fluids, diabetes status, etc.) that can impact insulin requirements when transitioning to subcutaneous insulin regimens.

\section{Conclusion}

Hyperglycemia has long been recognized as detrimental to patients who are critically ill. Ongoing research has demonstrated benefits to blood glucose targets that are less intensive and consequently may be less prone to hypoglycemia. Utilization of insulin via intravenous infusion is the most responsive to the acute needs of critically ill patients and is the most widely supported by literature. However, appropriate adjustment of insulin infusion requires frequent blood glucose monitoring. Newer technologies for glucose monitoring and insulin delivery may further improve glycemic management while decreasing caregiver workload.

\section{Acknowledgements}

The authors would like to thank Olivia Welter, PharmD, and Courtney Temple, PharmD, for their assistance with this manuscript.

\section{Conflicts of Interest}

The authors declare no conflicts of interest regarding the publication of this paper.

\section{References}

[1] Kavanaugh, B.P. and McCowen, K.C. (2010) Glycemic Control in the ICU. The 
New England Journal of Medicine, 363, 2540-2546.

https://doi.org/10.1056/NEJMcp1001115

[2] Moghissi, E.S., Korytkowski, M.T., DiNardo, M., Einhorn, D., Hellman, R., Hirsch, I.B., Inzucchi, S.E., Ismail-Beigi, F., Kirkman, M.S. and Umpierrez, G.E. (2009) American Association of Clinical Endocrinologists and American Diabetes Association Consensus Statement on Inpatient Glycemic Control. Diabetes Care, 32, 1119-1131. https://doi.org/10.2337/dc09-9029

[3] Kelly, J.L. (2014) Continuous Insulin Infusion: When, Where, and How? Diabetes Spectrum, 27, 218-223. https://doi.org/10.2337/diaspect.27.3.218

[4] Dombrowski, N.C. and Karounos, D.G. (2013) Pathophysiology and Management Strategies for Hyperglycemia for Patients with Acute Illness during and Following a Hospital Stay. Metabolism, 62, 326-336.

https://doi.org/10.1016/j.metabol.2012.07.020

[5] Dziedzic, T., Slowik, A., Pera, J. and Szczudlik, A. (2009) Association between Hyperglycemia, Heart Failure, and Mortality in Stroke Patients. European Journal of Neurology, 16, 251-256. https://doi.org/10.1111/j.1468-1331.2008.02400.x

[6] Moghissi, E.S., Korytkowski, M.T., DiNardo, M., Einhorn, D., Hellman, R., Hirsch, I.B., Inzucchi, S.E., Ismail-Beigi, F., Kirkman, M.S. and Umpierrez, G.E. (2009) American Association of Clinical Endocrinologists and American Diabetes Association Consensus Statement on Inpatient Glycemic Control. Endocrine Practice, 15, 353-369. https://doi.org/10.4158/EP09102.RA

[7] Falciglia, M., Freyburg, R.W., Almenoff, P.L., D’Alessio, D.A. and Render, M.L. (2009) Hyperglycemia-Related Mortality in Critically Ill Patients Varies with Admission Diagnosis. Critical Care Medicine, 37, 3001-3009.

https://doi.org/10.1097/CCM.0b013e3181b083f7

[8] Laird, A.M., Miller, P.R., Kilgo, P.D., Meredith, J.W. and Change, M.C. (2004) Relationship of Early Hyperglycemia to Mortality in Trauma Patients. The Journal of Trauma, 56, 1058-1062. https://doi.org/10.1097/01.TA.0000123267.39011.9F

[9] Krinsley, J.S. (2003) Association between Hyperglycemia and Increased Hospital Mortality in a Heterogeneous Population of Critically Ill Patients. Mayo Clinic Proceedings, 78, 1471-1478. https://doi.org/10.4065/78.12.1471

[10] Marfella, R., Siniscalchi, M., Esposito, K., Sellitto, A., De Fanis, U., Romano, C., Portoghese, M., Siciliano, S., Nappo, F., Sasso, F.C. and Mininni, N. (2003) Effects of Stress Hyperglycemia on Acute Myocardial Infarction: Role of Inflammatory Immune Process in Functional Cardiac Outcome. Diabetes Care, 26, 3129-3135. https://doi.org/10.2337/diacare.26.11.3129

[11] Dungan, K.M., Braithwaite, S.S. and Preiser, J.C. (2009) Stress Hyperglycemia. The Lancet, 373, 1798-1807. https://doi.org/10.1016/S0140-6736(09)60553-5

[12] Saand, A.R., Flores, M., Kewan, T., Alqaisi, S., Alwakeel, M., Griffiths, L., Wang, X., Han, X., Burton, R., Al-Jaghbeer, M.J. and Fadel, F.A. (2021) Does Inpatient Hyperglycemia Predict Worse Outcomes in COVID-19 Intensive Care Unit Patients? Journal of Diabetes, 13, 253-260. https://doi.org/10.1111/1753-0407.13137

[13] Godinjak, A., Iglica, A., Burekovic, A., Jusufovic, S., Ajanovic, A., Tancica, I. and Kukuljac, A. (2015) Hyperglycemia in Critically Ill Patients: Management and Prognosis. Medical Archives, 69, 157-160. https://doi.org/10.5455/medarh.2015.69.157-160

[14] Handelsman, Y., Bloomgarden, Z.T., Grunberger, G., Umpierrez, G., Zimmerman, R.S., Bailey, T.S., Blonde, L., Bray, G.A., Cohen, A.J., Dagogo-Jack, S., Davidson, J.A., Einhorn, D., Ganda, O.P., Garber, A.J., Garvey, W.T., Henry, R.R., Hirsch, I.B., Horton, E.S., Hurley, D.L., Jellinger, P.S., Jovanovič, L., Lebovitz, H.E., LeRoith, D., 
Levy, P., McGill, J.B., Mechanick, J.I., Mestman, J.H., Moghissi, E.S., Orzeck, E.A., Pessah-Pollack, R., Rosenblit, P.D., Vinik, A.I., Wyne, K. and Zangeneh, F. (2015) American Association of Clinical Endocrinologists and American College of Endocrinology-Clinical Practice Guidelines for Developing a Diabetes Mellitus Comprehensive Care Plan-2015. Endocrine Practice, 21, 1-87.

https://doi.org/10.4158/EP15672.GLSUPPL

[15] American Diabetes Association (2021) 15. Diabetes Care in the Hospital: Standards of Medical Care in Diabetes-2021. Diabetes Care, 44, S211-S220.

https://doi.org/10.2337/dc21-S015

[16] Jacobi, J., Bircher, N., Krinsley, J., Agus, M., Braithwaite, S.S., Deutschman, C., Freire, A.X., Geehan, D., Kohl, B., Nasraway, S.A., Rigby, M., Sands, K., Schallom, L., Taylor, B., Umpierrez, G., Mazuski, J. and Schunemann, H. (2012) Guidelines for the Use of an Insulin Infusion for the Management of Hyperglycemia in Critically Ill Patients. Critical Care Medicine, 40, 3251-3276.

https://doi.org/10.1097/CCM.0b013e3182653269

[17] Roberts, G.W., Aguilar-Loza, N., Esterman, A., Burt, M.G. and Stranks, S.N. (2012) Basal-Bolus Insulin versus Sliding-Scale Insulin for Inpatient Glycaemic Control: A Clinical Practice Comparison. The Medical Journal of Australia, 194, 266-269. https://doi.org/10.5694/mja11.10853

[18] Perez, A., Ramos, A. and Carreras, G. (2020) Insulin Therapy in Hospitalized Patients. American Journal of Therapeutics, 27, e71-e78.

https://doi.org/10.1097/MJT.0000000000001078

[19] Duggan, E.W., Carlson, K. and Umpierrez, G.E. (2017) Perioperative Hyperglycemia Management: An Update. Anesthesiology, 126, 547-560. https://doi.org/10.1097/ALN.0000000000001515

[20] Bilotta, F., Badenas, R., Lolli, S., Belda, F.J., Einav, S. and Rosa, G. (2015) Insulin Infusion Therapy in Critical Care Patients: Regular Insulin vs. Short-Acting Insulin. A Prospective, Crossover, Randomized, Multicenter Blind Study. Journal of Critical Care, 30, 437.e1-6. https://doi.org/10.1016/j.jcrc.2014.10.019

[21] Masood, M.Q., Batool, S., Banu, S. and Hussain, E. (2021) Efficacy and Safety of a New Insulin Infusion Protocol Adapted for the Target Glycemic Range of 140-180 $\mathrm{mg} / \mathrm{dl}$ in Adult Critical Care Units: A Tertiary Care Centre Experience. International Journal of Diabetes in Developing Countries, 41, 469-475. https://doi.org/10.1007/s13410-020-00915-3

[22] Van den Berghe, G., Wouters, P., Weekers, F., Verwaest, C., Bruyninckx, F., Schetz, M., Vlasselaers, D., Ferdinande, P., Lauwers, P. and Bouillon, R. (2001) Intensive Insulin Therapy in Critically Ill Patients. The New England Journal of Medicine, 345, 1359-1367. https://doi.org/10.1056/NEJMoa011300

[23] Van den Berghe, G., Wilmer, A., Hermans, G., Meersseman, W., Wouters, P.J., Milants, I., Van Wijngaerden, E., Bobbaers, H. and Bouillon, R. (2006) Intensive Insulin Therapy in the Medical ICU. The New England Journal of Medicine, 354, 449-461. https://doi.org/10.1056/NEJMoa052521

[24] American Diabetes Association (2008) Standards of Medical Care in Diabetes-2008. Diabetes Care, 31, S12-S54. https://doi.org/10.2337/dc08-S012

[25] The NICE-SUGAR Study Investigators (2009) Intensive versus Conventional Glucose Control in Critically Ill Patients. The New England Journal of Medicine, 360, 1283-1297. https://doi.org/10.1056/NEJMoa0810625

[26] Griesdale, D.E.G., de Souza, R.J., van Dam, R.M., Daren, K., Heyland, D.K., Cook, D.J., Malhotra, A., Dhaliwal, R., Henderson, W.R., Chittock, D.R., Finfer, S. and 
Talmor, D. (2009) Intensive Insulin Therapy and Mortality among Critically Ill Patients: A Meta-Analysis Including NICE-SUGAR Study Data. The Canadian Medical Association Journal, 180, 821-827. https://doi.org/10.1503/cmaj.090206

[27] The NICE-SUGAR Study Investigators (2012) Hypoglycemia and Risk of Death in Critically Ill Patients. The New England Journal of Medicine, 367, 1108-1118. https://doi.org/10.1056/NEJMoa1204942

[28] The NICE-SUGAR Study Investigators (2015) Intensive versus Conventional Glucose Control in Critically Ill Patients with Traumatic Brain Injury: Long-Term Follow-Up of a Subgroup of Patients from the NICE-SUGAR Study. Intensive Care Medicine, 41, 1037-1047. https://doi.org/10.1007/s00134-015-3757-6

[29] Krinsley, J.S. (2015) Glycemic Control in the Critically Ill: What Have We Learned since NICE-SUGAR? Hospital Practice, 43, 191-197.

https://doi.org/10.1080/21548331.2015.1066227

[30] Galindo, R.J., Umpierrez, G.E., Rushakoff, R.J., Basu, A., Lohnes, S., Nichols, J.H., Spanakis, E.K., Espinoza, J., Palermo, N.E., Awadjie, D.G., Bak, L., Buckingham, B., Cook, C.B., Freckmann, G., Heinemann, L., Hovorka, R., Mathioudakis, N., Newman, T., O’Neal, D.N., Rickert, M., Sacks, D.B., Seley, J.J., Wallia, A., Shang, T., Zhang, J.Y., Han, J. and Klonoff, D.C. (2020) Continuous Glucose Monitors and Automated Insulin Dosing Systems in the Hospital Consensus Guideline. Journal of Diabetes Science and Technology, 14, 1035-1064.

https://doi.org/10.1177/1932296820954163

[31] Lu, M., Zuo, Y., Guo, J., Wen, X. and Kang, Y. (2018) Continuous Glucose Monitoring System Can Improve the Quality of Glucose Control and Glucose Variability Compared with Point-of-Care Measurement in Critically Ill Patients: A Randomized Controlled Trial. Medicine (Baltimore), 97, e12138. https://doi.org/10.1097/MD.0000000000012138

[32] Boom, D.T., Sechterberger, M.K., Rijkenberg, S., Kreder, S., Bosman, R.J., Wester, J.P., van Stijn, I., DeVries, J.H. and van der Voort, P.H. (2014) Insulin Treatment Guided by Subcutaneous Continuous Glucose Monitoring Compared to Frequent Point-of-Care Measurement in Critically Ill Patients: A Randomized Controlled Trial. Critical Care, 18, Article No. 453. https://doi.org/10.1186/s13054-014-0453-9

[33] Tanenberg, R.J., Hardee, S., Rothermel, C. and Drake, A.J. (2017) Use of a Computer-Guided Glucose Management System to Improve Glycemic Control and Address National Quality Measures: A 7-Year Retrospective Observational Study at a Tertiary Care Teaching Hospital. Endocrine Practice, 23, 331-341.

https://doi.org/10.4158/EP161402.OR

[34] Dubois, J., Van Herpe, T., van Hooijdonk, R.T., Wouters, R., Coart, D., Wouters, P., Van Assche, A., Veraghtert, G., De Moor, B., Wauters, J., Wilmer, A., Schultz, M.J., Van den Berghe, G. and Mesotten, D. (2017) Software-Guided versus Nurse-Directed Blood Glucose Control in Critically Ill Patients: The LOGIC-2 Multicenter Randomized Controlled Clinical Trial. Critical Care, 21, Article No. 212. https://doi.org/10.1186/s13054-017-1799-6

[35] Hashemi, N., Valk, T., Houlind, K. and Ejskjaer, N. (2019) Insulin-Based Infusion System: Advancing the Development. Journal of Diabetes Science and Technology, 13, 941-948. https://doi.org/10.1177/1932296819832876

[36] Umpierrez, G.E., Hellman, R., Korytkowski, M.T., Kosiborod, M., Maynard, G.A., Montori, V.M., Seley, J.J., Van den Berghe, G. and Endocrine Society (2012) Management of Hyperglycemia in Hospitalized Patients in Non-Critical Care Settings: An Endocrine Society Clinical Practice Guideline. The Journal of Clinical Endocrinology \& Metabolism, 97, 16-38. https://doi.org/10.1210/jc.2011-2098 
[37] Avanzini, F., Marelli, G., Donzelli, W., Busi, G., Carbone, S., Bellato, L., Colombo, E.L., Foschi, R., Riva, E., Roncaglioni, M.C., De Martini, M. and Desio Diabetes Diagram Study Group (2011) Transition from Intravenous to Subcutaneous Insulin. Diabetes Care, 34, 1445-1450. https://doi.org/10.2337/dc10-2023

[38] Doolin, M.K., Walroth, T.A., Harris, S.A., Whitten, J.A. and Fritschle-Hilliard, A.C. (2016) Transition from Intravenous to Subcutaneous Insulin in Critically Ill Adults. Journal of Diabetes Science and Technology, 10, 932-938.

https://doi.org/10.1177/1932296816629985 